\title{
Dopamine Reuptake Inhibition in the Rostral Agranular Insular Cortex Produces Antinociception
}

\author{
Adam R. Burkey, ${ }^{1}$ Earl Carstens, ${ }^{3}$ and Luc Jasmin ${ }^{1,2}$ \\ ${ }^{1}$ Departments of Neurosurgery and ${ }^{2}$ Cell Biology, Georgetown University Medical Center, Washington, DC 20007, and \\ 3Section of Neurobiology, Physiology and Behavior, University of California at Davis, Davis, California 95616
}

We provide evidence for an antinociceptive effect of dopamine in the rat cerebral cortex that is mediated through descending nociceptive inhibition of spinal neurons. Injection of the dopamine reuptake inhibitor GBR-12935 in the rostral agranular insular cortex (RAIC), a cortical area that receives a dense dopaminergic projection and is involved in descending antinociception (Burkey et al., 1996), resulted in dose-dependent inhibition of formalin-induced nociceptive behavior, without any alteration of motor function. Injection of the dopamine reuptake inhibitor in the surrounding cortical areas had no effect on nociceptive behaviors. GBR-12935 also produced a reduction in noxious stimulus-induced $c$-fos expression in nociceptive areas of the spinal dorsal horn, suggesting that dopamine in the RAIC acts in part through descending antinociception. Electro- physiological recording from single wide dynamic range-type spinal dorsal horn neurons confirmed the descending nociceptive inhibitory effect. GBR-12935 in the RAIC significantly reduced neuronal responses evoked by noxious thermal stimulation of the skin, an effect that was reversed by local administration of the selective $\mathrm{D} 1$ receptor antagonist $\mathrm{SCH}-$ 23390. Finally, administration of SCH-23390 alone in the RAIC decreased paw withdrawal latencies from noxious heat, suggesting that dopamine acts tonically in the cortex to inhibit nociception.

Key words: pain; cerebral cortex; descending inhibition; D1 receptor; dopamine reuptake inhibitor; GBR-12935; dopamine antagonist; SCH-23390
The role of the cerebral cortex in analgesia is only beginning to be defined. In the rat, cortical areas that activate endogenous descending antinociceptive systems include the rostral agranular insular cortex (RAIC) (Burkey et al., 1996), the ventrolateral orbital cortex (Backonja and Miletic, 1991; Snow et al., 1992; Backonja et al., 1994), and the medial prefrontal cortex (Hardy, 1985). These cortical areas are part of the mesolimbic/mesocortical ventral forebrain circuits, through which dopamine has been shown to affect cognition and mood (Suhara et al., 1992; Larisch et al., 1997; Watanabe et al., 1997; Goldman-Rakic, 1998). Because nociceptive stimuli increase the activity of mesocortical and mesolimbic neurons and the local release of dopamine (Mantz et al., 1989; Cenci et al., 1992; Altier and Stewart, 1998), these forebrain circuits might also modulate nociception. Although an antinociceptive action of dopamine in the cortex has not been reported, in nucleus accumbens increasing the release of dopamine is antinociceptive, an effect mediated through D1 and D2 dopamine receptors (Altier and Stewart, 1993, 1998). In addition to its stimulus-induced antinociceptive effects, dopamine may also tonically inhibit nociception in the mesolimbic/mesocortical circuits, because lesion of the dopaminergic neurons of the ventral tegmental area (VTA) results in hyperalgesic responses and

\footnotetext{
Received Feb. 8, 1998; revised March 3, 1999; accepted March 9, 1999.

This research was supported by grants from the National Institute of Neurological Disorders and Stroke (NS-35778), the California Tobacco Disease-Related Research Program (6RT-0231), the Medical Research Council (Canada), and the Howard Hughes Medical Institute. We thank Ms. Jinwen Tang and Dr. Lian Sheng Liu for their expert technical assistance and Gabriella Janni for editorial assistance. Correspondence should be addressed to Dr. Luc Jasmin, Research Building, W221, Georgetown University Medical Center, 3970 Reservoir Road NW, Washington, DC 20007.

Copyright (C) 1999 Society for Neuroscience $\quad 0270-6474 / 99 / 194169-11 \$ 05.00 / 0$
}

an increase in self-mutilating behavior after deafferentation (Saadé et al., 1997).

Indication for a behavioral effect of dopaminergic input to the RAIC has previously been obtained after local dopamine depletion abolished morphine-induced conditioned taste aversion (Zito et al., 1988) and self-stimulation through locally implanted electrodes (Clavier and Gerfen, 1979). Furthermore, the RAIC harbors a local concentration of D1 and, in lesser quantity, D2 receptors (Richfield et al., 1989; Gaspar et al., 1995). Compared with the medial prefrontal cortex and nucleus accumbens, the RAIC is the site of highest dopamine release and metabolism, as well as of high activity of dopamine-sensitive adenylate cyclase (Tassin et al., 1978; Jones et al., 1986).

On the basis of these previous findings, we determined the effect of increasing endogenous dopamine in the RAIC on nociceptive behavior and activity of spinal nociceptive neurons. We also determined whether there was a tonic antinociceptive effect of dopamine in the RAIC.

\section{MATERIALS AND METHODS}

Male Sprague Dawley rats $(n=171 ; 270-320$ gm; Harlan Sprague Dawley, Indianapolis, IN) were used in this study. All animals were exposed to light $12 \mathrm{hr} / \mathrm{d}$; food and water were available ad libitum. Procedures for the maintenance and use of the experimental animals were approved by the Animal Care and Use Advisory Committee at Georgetown University and at the University of California, Davis, and were performed in accordance with National Institutes of Health regulations on animal use.

Implantation of intracerebral cannulae. Because unilateral stimulation of the RAIC produces bilateral antinociception (Burkey et al., 1996), cannulae implantation was unilateral only. Animals were anesthetized with a mixture of $1.5 \%$ halothane and pure oxygen delivered through a face mask and placed in a stereotaxic frame. A stainless steel cannula (26 gauge, Plastics One; Roanoke, VA) was positioned above a burr hole drilled over the RAIC according to the following stereotaxic coordi- 
nates: rostrocaudal, 11.0; lateral, 3.5; dorsoventral, 2.6 (Paxinos and Watson, 1986). Two skull screws were inserted into the calvarium and used to cement the cannula in place with dental acrylic. All animals were allowed at least $3 \mathrm{~d}$ to recover before behavioral testing.

On the day of testing, a 33 gauge internal cannula was inserted through the guide cannula to a distance $6.2 \mathrm{~mm}$ beyond the pedestal. Drugs were then slowly inf used through polyethylene tubing (PE-50; inner diameter, $0.58 \mathrm{~mm}$ ) connected to the injection cannula using a $1.0 \mu$ l Hamilton syringe driven by a microinfusion pump. The infusion was made at a constant rate over a period of $4 \mathrm{~min}$, after which the polyethylene tube was cut and the cannula left in place. Because of the short length of the guide cannulae (to avoid cerebral damage), the tendency of the 33 gauge cannulae to bend, and the small size of the targeted area, on-site (i.e., in the RAIC, see Figs. 1, 2, and 3) cannulae placement was obtained in only $\sim 50 \%$ of the animals, as determined by post hoc histological analysis (by two persons blind to the behavioral score). During behavioral trials, experimenters were therefore blind to the injection site (i.e., "on-site" vs "off-site").

Formalin nociceptive behavior in rats receiving GBR-12935 in the RAIC. On the day before nociceptive behavioral testing, the animals were acclimated for $1 \mathrm{hr}$ to the testing chambers suspended above a mirror positioned to view the plantar aspect of the hindpaws. On the day of behavioral testing, GBR-12935 (4.1, 8.2, or $16.4 \mathrm{nmol} / 400 \mathrm{nl}$ PBS) or vehicle was injected through the internal cannula into the agranular insular cortex. Ten minutes thereafter, $50 \mu \mathrm{l}$ of a $2 \%$ formalin solution in PBS, pH 7.4, was injected subcutaneously with a 30 gauge hypodermic needle in the medial third of the plantar aspect of the hindpaw between the second and third toe. The animal was then immediately placed into the testing chamber and observed continuously for $1 \mathrm{hr}$, during which the nociceptive behavior was assessed according to a standard scoring method (Dubuisson and Dennis, 1977). Data were collected using a computer program (derived from an algorithm provided by Dr. Terence Coderre, Clinical Research Institute of Montréal, Montréal, Canada) that automatically calculates average behavior scores in successive $5 \mathrm{~min}$ bins. The significance of the numerical scores is given below: 0 , normal gait and full weight bearing on the injured paw; 1 , the injured paw rests lightly on the ground and toes are not splayed; 2 , the injured paw is lifted completely off the floor; 3 , the injured paw is licked, shaken, or bitten.

After the testing hour, the animals were deeply anesthetized with an intramuscular injection of ketamine $(87 \mathrm{mg} / \mathrm{kg})$ and xylazine $(13 \mathrm{mg} / \mathrm{kg})$ and perfused through the ascending aorta with Tyrode's buffer followed by $10 \%$ formalin. The brain and lumbar spinal cord were then dissected and post-fixed in $10 \%$ formalin for $4 \mathrm{hr}$, after which the tissue was marked on the right side by a small wedge made with a no. 11 blade, then cryoprotected in $30 \%$ sucrose for at least $48 \mathrm{hr}$ and transversely sectioned on a freezing microtome ( $40 \mu \mathrm{m}$ thick for the spinal cord, $100 \mu \mathrm{m}$ thick for the brain).

Paw withdrawal from noxious heat and motor function were assessed in an additional 10 rats injected with the high dose of GBR-12935 (16.4 nmol) as described below.

Electrophysiological experiments. Animals were anesthetized with pentobarbital $(50 \mathrm{mg} / \mathrm{kg}$, i.p.), and a PE-50 polyethylene tube was then placed in the internal jugular vein for continuous Nembutal infusion $\left(10-20 \mathrm{mg} \cdot \mathrm{kg}^{-1} \cdot \mathrm{hr}^{-1}\right)$ to maintain areflexia throughout the experiment (4-6 hr). The spinal cord was exposed and the dura reflected. The animals were suspended in a stereotaxic frame with ear bars and vertebral clamps. An agar well was made around the exposed cord and filled with sterile saline $(0.9 \%)$. A burr hole was drilled above the RAIC and a Hamilton syringe with a glass micropipette (tip diameter $40 \mu \mathrm{m}$ ) containing GBR-12935 (8.2 nmol/400 nl) was held above in a stereotaxic arm. Spinal lumbar dorsal horn recordings were made with a tungsten microelectrode $(10 \mathrm{M} \Omega)$ attached to a microdriver. We sought neurons that responded to mechanical stimulation of the ipsilateral hindpaw and additionally to noxious thermal $\left(48^{\circ} \mathrm{C}, 5 \mathrm{sec}\right.$ duration) heating delivered with a $1 \times 1 \mathrm{~cm}$ Peltier thermode placed against skin within the unit's receptive field. Units were thus classified as wide dynamic range (WDR) type. Isolated extracellular action potentials were amplified and displayed by conventional means and discriminated and stored by use of Spike software (Forster and Handwerker, 1990) for subsequent construction of peristimulus-time histograms (PSTHs) (bin width, $1 \mathrm{sec}$ ). Responses to the $5 \mathrm{sec}, 50^{\circ} \mathrm{C}$ heat stimulus were quantified by counting the total number of action potentials during the $10 \mathrm{sec}$ period beginning with heat onset. After establishment of baseline (approximately six heat trials), the glass micropipette was lowered to the coordinates of the RAIC and GBR-12935 was slowly injected. Responses to noxious heat application were recorded at $3 \mathrm{~min}$ intervals throughout. If neuronal firing was unaffected by injection, the coordinates were noted, and the pipette tip was moved to new coordinates after allowing $1 \mathrm{hr}$ for the drug to clear from the brain. If a reduction in firing was observed, no new trajectory was made, and the pipette was left in place to inject the selective D1 antagonist SCH-23390 (12 nmol/400 nl) after $\sim 40 \mathrm{~min}$. The experiment was then concluded by the injection in this effective site of 1 $\mathrm{nl}$ of biotin dextran $10 \%$. Postmortem, the brains were cut transversely (40 $\mu \mathrm{m}$ thick) and sections kept in rostrocaudal order for ensuing analysis. Each section was then submitted to an ABC-nickel-DAB procedure, as described below in Immunocytochemistry, and counterstained with cresyl violet. Analysis of the pipette tracks on contiguous serial transverse sections of the brain and comparison with the logged stereotaxic coordinate identified the location and ending of each pipette trajectory. Effective sites were easily recognized by the presence of dark-black nickel-DAB deposits.

Thermal nociceptive testing and motor testing. We evaluated the sensory and motor effects of GBR-12935 or the D1-receptor antagonist (SCH23390) injected in the RAIC. Sensory responses were assessed using thermal paw withdrawal testing, and motor function was scored with a rotarod. Of note, paw skin temperatures at 15 and $45 \mathrm{~min}$, measured as described previously (Jasmin et al., 1998), did not differ between drugand vehicle-treated groups (data not shown). This result suggests the absence of vascular effects of SCH-23390 in the RAIC, and is in agreement with the previous report that administration of a D1 or D2 receptor antagonist in the same cortical area does not affect heart rate or systemic blood pressure (Funk and Stewart, 1996).

Five days before testing, a guide cannula was stereotaxically implanted according to the protocol described above. On days 3 and 4 after cannula implantation, the animals were trained for $1 \mathrm{hr}$ on the rotarod (Ugo Basile Co.; circumference $18.5 \mathrm{~cm}$ ) and acclimated to the Plexiglas thermal paw withdrawal chamber $(22 \times 17 \times 13 \mathrm{~cm}$; Plantar Analgesia Instrument, Ugo Basile Co.). The instrument was calibrated after each testing day and set to 30 infrared units corresponding to $150 \mathrm{mcal} / \mathrm{sec}$ per $\mathrm{cm}^{2}$ (Ugo Basile, personal communication), and the glass surface on which the animals rested was maintained at a constant temperature of $27^{\circ} \mathrm{C}$.

Behavioral testing was performed over $2 \mathrm{~d}$. Baseline sensory and motor scores were obtained on the first day. On the second day, 20 min after intracerebral microinjection of GBR-12935 (16.4 nmol/400 nl PBS) or 15 min after SCH-23390 $(0.24,1.2$, or $6.0 \mathrm{nmol} / 400 \mathrm{nl}$ double-distilled water; only one dose per animal; rats receiving the same dose were tested on the same day), thermal stimuli (three to five trials per paw) were delivered to the middle third of the plantar aspect of the hindpaw, with a $5 \mathrm{~min}$ interval between stimuli to the same limb. The stimulus was terminated at $10 \mathrm{sec}$ in the absence of any paw withdrawal to avoid tissue damage. The latency to paw withdrawal was recorded with a precision of $0.10 \mathrm{sec}$.

Testing continued until $35 \mathrm{~min}$ (GBR-12935) or $45 \mathrm{~min}$ (SCH-23390) after infusion, at which time the animals were immediately transferred to the rotarod for motor testing (Main et al., 1995), where six trials were conducted per animal. The rotarod was set at a constant low speed (60 $\mathrm{cm} / \mathrm{min}$ ) before the rats were positioned on the apparatus. Once all animals were positioned and walking, the rotarod was changed to an accelerating mode to a cutoff speed of $108 \mathrm{~cm} / \mathrm{min}$ at $5 \mathrm{~min}$. The maximal time, in seconds, during which each animal was able to remain on the rotarod was recorded for each trial by a treatment-blind observer. The entire sensory-motor testing procedure took $\sim 40 \mathrm{~min}$ for GBR-12935 and $90 \mathrm{~min}$ for SCH-23390, within the limits of the biological half-life of each drug (McQuade et al., 1991).

Immunocytochemistry. Immunolabeling of tyrosine hydroxylase (TH) and dopamine- $\beta$-hydroxylase fibers in the RAIC was performed with polyclonal rabbit antisera (Eugene Tech), applied at a dilution of $1: 10,000$ and $1: 4000$, respectively, to $100 \mu \mathrm{m}$ brain serial transverse sections from three normal, untreated rats. Sections were immersed in a blocking solution made of 3\% normal goat serum and $0.3 \%$ Triton X-100 in PBS for $1 \mathrm{hr}$ and then incubated for $48 \mathrm{hr}$ at $4^{\circ} \mathrm{C}$ with the rabbit antiserum, after which the tissue was washed and exposed to a biotinylated secondary goat anti-rabbit IgG (Vector Labs, Burlingame, CA) and then to an avidin-biotin-peroxidase complex (ABC, Vector Labs). A nickel-diaminobenzidine (DAB) glucose oxidase reaction was used to visualize the immunocomplex (Llewellyn-Smith and Minson, 1992). Alternate sections were counterstained with cresyl violet. All sections were then mounted on gelatin-coated glass slides, dried, dehydrated in graded alcohol, cleared in xylene, and coverslipped. In control wells, omitting the 
primary antiserum eliminated the immunoreactivity for both $\mathrm{TH}$ and dopamine- $\beta$-hydroxylase.

Lumbar spinal cords $(n=22)$ of animals subjected to formalin testing after injections of 8.2 nmol of GBR-12935 $(n=17)$ or vehicle $(n=5)$ into the rostral insular cortex were randomly selected for the Fos immunostaining. Transverse sections of the lumbar cord $(40 \mu \mathrm{m})$ were immunostained for the Fos antigen using a rabbit polyclonal antiserum directed against an in vitro translated protein product of the $c$-fos gene (a generous gift from Dr. Dennis Slamon, Departments of Hematology and Oncology, University of California Los Angeles) at a dilution of 1:21,000. This antiserum does not recognize the Fos-related antigens and is devoid of any background staining. The same procedure as described above was used for TH immunocytochemistry (Burkey et al., 1996).

Quantification of Fos immunolabeling in rats receiving GBR-12935 in the $R A I C$ and submitted to a formalin test. Fos immunoreactive neurons were counted by a treatment-blind individual. Each section was analyzed under the microscope and drawn using a camera lucida attachment. Dark-field illumination was used to identify the borders of lamina II (substantia gelatinosa) and of the reticulated area of the neck of the dorsal horn. The rostrocaudal level was determined according to the criteria of Molander and colleagues (1984). Counts of Fos immunoreactive neurons were made in three regions at the L4-5 levels: (1) the superficial dorsal horn, lamina I and outer lamina II (IIo); (2) the neck of the dorsal horn, lamina $\mathrm{V}$ and adjacent portions of laminae IV and VI; and (3) the central canal area (CC). Because of a relatively low variance in the mean number of Fos-immunoreactive cells per section, the number of Fos-immunoreactive cells for each animal in each of the three spinal areas was averaged from counts on six randomly selected sections. The number of Fos-immunoreactive cells in each of the three regions was then averaged for each animal.

Data and statistical analysis. All data are presented as the mean \pm SEM. ANOVA was used to determine statistically significant differences in formalin test behavior, thermal paw withdrawal latencies, rotarod behavior, and Fos immunolabeling between groups injected with drug or vehicle, on-site or off-site. In electrophysiological experiments, data were grouped by on-site and off-site locations of brain microinjections, and averaged responses after drug injection were compared with pre-drug baselines using unpaired $t$ tests and ANOVA. All statistical analyses were performed with StatView (Abacus Concepts, Berkeley, CA). For all analyses, statistical significance was considered if $p<0.05$.

\section{RESULTS}

\section{Boundaries of the RAIC area inducing antinociception}

Because the purpose of our study was the investigation of the role of a specific cortical area in nociception, we needed to define from the outset the limits of the area in which drug effects were to be evaluated (Fig. 1). This area corresponds to the previously identified specific portion of the RAIC, within the limits of which morphine injection produced antinociception (Burkey et al., 1996). Another defining characteristic of this portion of the RAIC is that it coincides with the area of dense catecholaminergic innervation of the insular cortex (Fig. 2).

\section{Catecholaminergic innervation of the RAIC}

Comparison of immunolabeling for $\mathrm{TH}$ and dopamine- $\beta$ hydroxylase was used to assess the distribution of dopaminergic versus noradrenergic fibers in the RAIC. Compared with the surrounding cortex, most of the TH labeled terminals were concentrated within the boundaries of the RAIC. Few THimmunopositive fiber-like profiles were seen in the adjacent dysgranular, piriform, and orbital cortices (Fig. $2 A$ ). In the RAIC, TH immunoreactivity labeled fine fiber-like profiles that were most abundant in laminae 5 and 6 , in addition to being present in other laminae (Fig. $2 B$ ). In comparison to $\mathrm{TH}$, dopamine- $\beta$ hydroxylase fiber-like immunoreactivity was sparse and more evenly distributed throughout all laminae and divisions of the insular cortex (agranular, dysgranular, and granular). Because of the predominant $\mathrm{TH}$ compared with dopamine- $\beta$-hydroxylase immunoreactivity, we concluded that most of the TH immunore- activity reflects dopaminergic fibers and terminals from the VTA. This is in agreement with Akil and Lewis (1993), who found that $<1 \%$ of TH-positive axons in the monkey's cortex were also dopamine- $\beta$-hydroxylase-immunopositive. The location of most dopamine terminals in the inner laminae of the RAIC is consistent with the local distribution of dopamine receptors (Gaspar et al., 1995).

\section{Antinociceptive effect of GBR-12935 in the RAIC and its mediation by descending inhibitory control}

Formalin nociceptive behavior

Rats $(n=102)$ were subjected to formalin nociceptive testing after microinjection of the dopamine reuptake inhibitor GBR12935 (4.1, 8.2, or $16.4 \mathrm{nmol} / 400 \mathrm{nl})$ or its vehicle (400 nl PBS) in the area of the rostral insular cortex (Fig. $3 A$ ). Post hoc analysis revealed that compared with vehicle-injected animals, all rats with on-site injections receiving the middle or high doses showed significant antinociception $(p<0.05)$ (Fig. 3B,C). The average 60 min formalin scores of on-site injections were $1.5 \pm 0.2(n=4)$, $1.1 \pm 0.1(n=23)$, and $0.7 \pm 0.1(n=6)$ for the 4.1, 8.2, and 16.4 nmol groups, respectively. None of the on-site injections for the lower dose and none of the off-site injections for all three doses resulted in an antinociceptive effect. Scores for the off-site groups were $1.4 \pm 0.2(n=6), 1.6 \pm 0.1(n=33)$, and $1.4 \pm 0.1(n=4)$ for the 4.1, 8.2, and $16.4 \mathrm{nmol}$ groups, respectively. In the vehicleinjected group, no difference in the behavioral scores was found between rats injected on-site $(1.4 \pm 0.1, n=14)$ or off-site $(1.3 \pm$ $0.1, n=12$ ). When the scores were plotted (Fig. $3 B$ ), the average differences between groups were present throughout most of the 60 min period, together with a persistence of the characteristic biphasic time-dependent aspect of the formalin curve (Dubuisson and Dennis, 1977). This localized cortical site of action of the dopamine reuptake inhibitor is coincident with a localized dense dopaminergic projection to the RAIC (Divac et al., 1978; Descarries et al., 1987; Van Eden et al., 1987). Finally, in 10 rats not submitted to a formalin test, a baseline latency to withdraw the hindpaw from a radiant heat source was obtained $(3.6 \pm 0.4 \mathrm{sec})$. The same rats were trained on the rotarod for $3 \mathrm{~d}$ until they were able to stay in equilibrium for $300 \mathrm{sec}$. On the experimental day they received $16.4 \mathrm{nmol}$ of GBR-12935 in the RAIC. Twenty minutes after injection, heat withdrawal latencies were assessed in the contralateral hindpaw $(\times 3)$. Six animals had significantly increased withdrawal latencies $(8.1 \pm 0.3 \mathrm{sec}, p<0.05)$, whereas the latencies of the four others did not differ from the pre-drug values $(3.8 \pm 0.4 \mathrm{sec}, p>0.05)$. The animals were then immediately tested on the rotarod, $35 \mathrm{~min}$ after receiving GBR-12935. None of the animals showed a motor deficit. Analysis of the cannula tracts in the animals tested for heat and motor behavior showed that in six rats, GBR-12935 was injected in the RAIC, whereas in the four others it was injected in the ventrolateral orbital cortex $(n=2)$ and the dysgranular cortex $(n=2)$. The six on-site injected animals were the ones presenting increased withdrawal latencies to nociceptive heat.

\section{Stimulus-induced Fos-immunoreactive cells in the lumbar spinal cord}

In 22 rats injected with 8.2 nmol of GBR-12935, counts of Fosimmunopositive cells in nociceptive areas of the caudal lumbar spinal cord (Menétrey, 1987) were compared among vehicleinjected rats $(n=5)$, those injected on-site $(n=11)$, and those injected off-site $(n=6)$. When compared with off-site and vehicleinjected controls, rats injected with GBR-12935 on-site demon- 
Figure 1. Landmarks of the RAIC that were used to define the "on-site" injections. $A$, Low power of a Nissl-stained transverse brain section through the middle third of the RAIC. The dorsal and ventral borders of the RAIC are delineated by the continuous bottom two lines. The RAIC's ventral border extends laterally from the medial part of the rhinal fissure $(r f)$ to the ventral tip of the claustrum $(C L A)$. This ventral border marks the end of the four-layer transitional cortex, which becomes the three-layered piriform cortex (Pir). Dorsally, the border between the RAIC and the dysgranular insular cortex $(D I C)$ is a line that extends perpendicularly from the cortical surface to the junction between the middle and dorsal third of the claustrum. Although a nascent lamina 4 is recognized in the differential interference contrast, it is well developed dorsally and serves to mark the border (top full line) with the granular insular cortex (GIC). The cortical layers are indicated in arabic numerals. $B$, Diagrams of transverse brain sections modified from the atlas of Swanson (1992). The gray areas between continuous lines represent the RAIC. Laminae 1-6 are delineated by interrupted lines. The rostrocaudal levels of each section according to Swanson's atlas are indicated under each section. $C$, Whole transverse section of the right hemisphere, showing the injection site of the D1 receptor antagonist SCH-23390 (arrow). The boxed area delineates an area equivalent to that included in $A$. This animal displayed clear hyperalgesia to nociceptive heat in addition to allodynia to light touch. $a c$, Anterior commissure; $C P$, caudate-putamen; $e c$, external capsule; $f a$, anterior forceps of the corpus callosum; VLO, ventrolateral orbital cortex. Scale bar (shown in $B): A, 200 \mu \mathrm{m} ; B, 1.7 \mathrm{~mm}$.
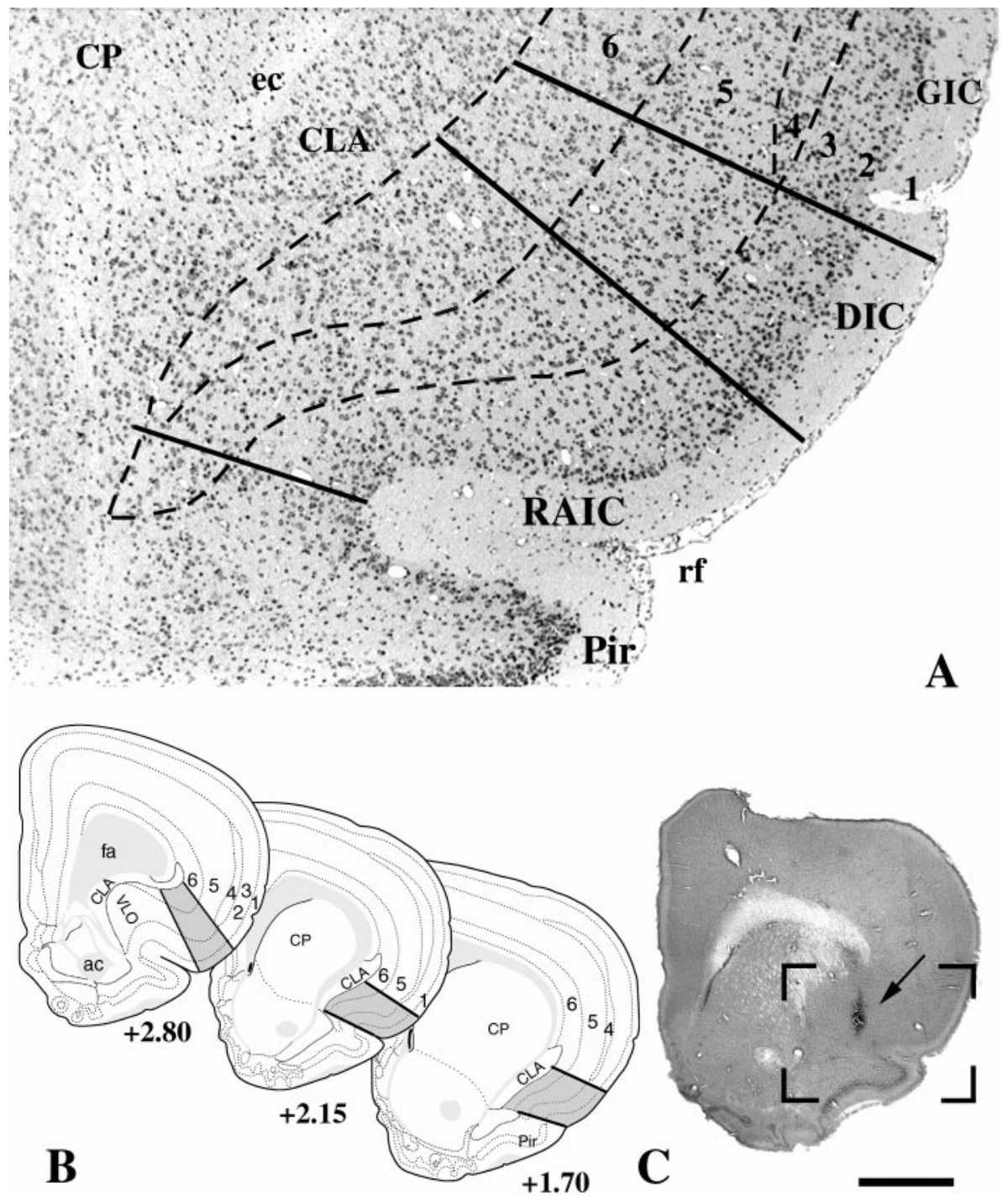

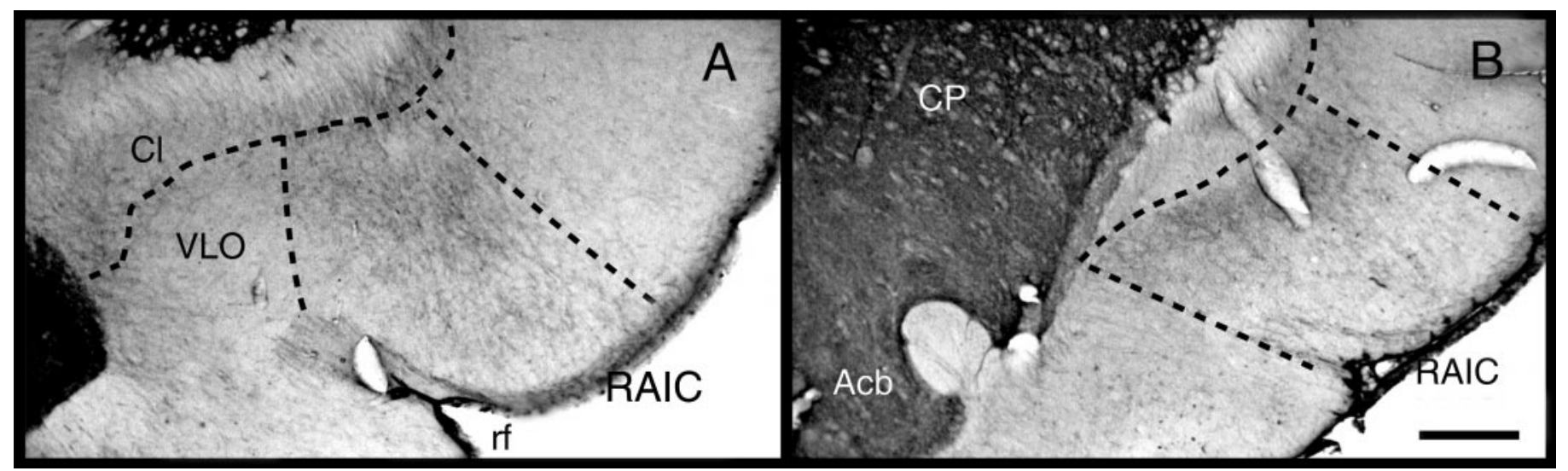

Figure 2. TH immunocytochemistry demonstrating catecholaminergic cortical afferents. The projection is mainly localized to the RAIC, the limits of which are indicated by interrupted lines. At high power (data not shown), these areas contain intermeshed fiber-like immunolabeled profiles. Although rostrally $(A$, level +2.80 of Swanson's atlas) and caudally $(B$, level +2.15 of Swanson's atlas), labeling is denser in the inner laminae (5 and 6$)$, it is also present in other laminae. Medially to the RAIC, nucleus accumbens $(A c b)$ and caudate-putamen $(C P)$ are very densely labeled, corresponding to their abundant catecholaminergic afferents. Scale bar, $200 \mu \mathrm{m}$. 

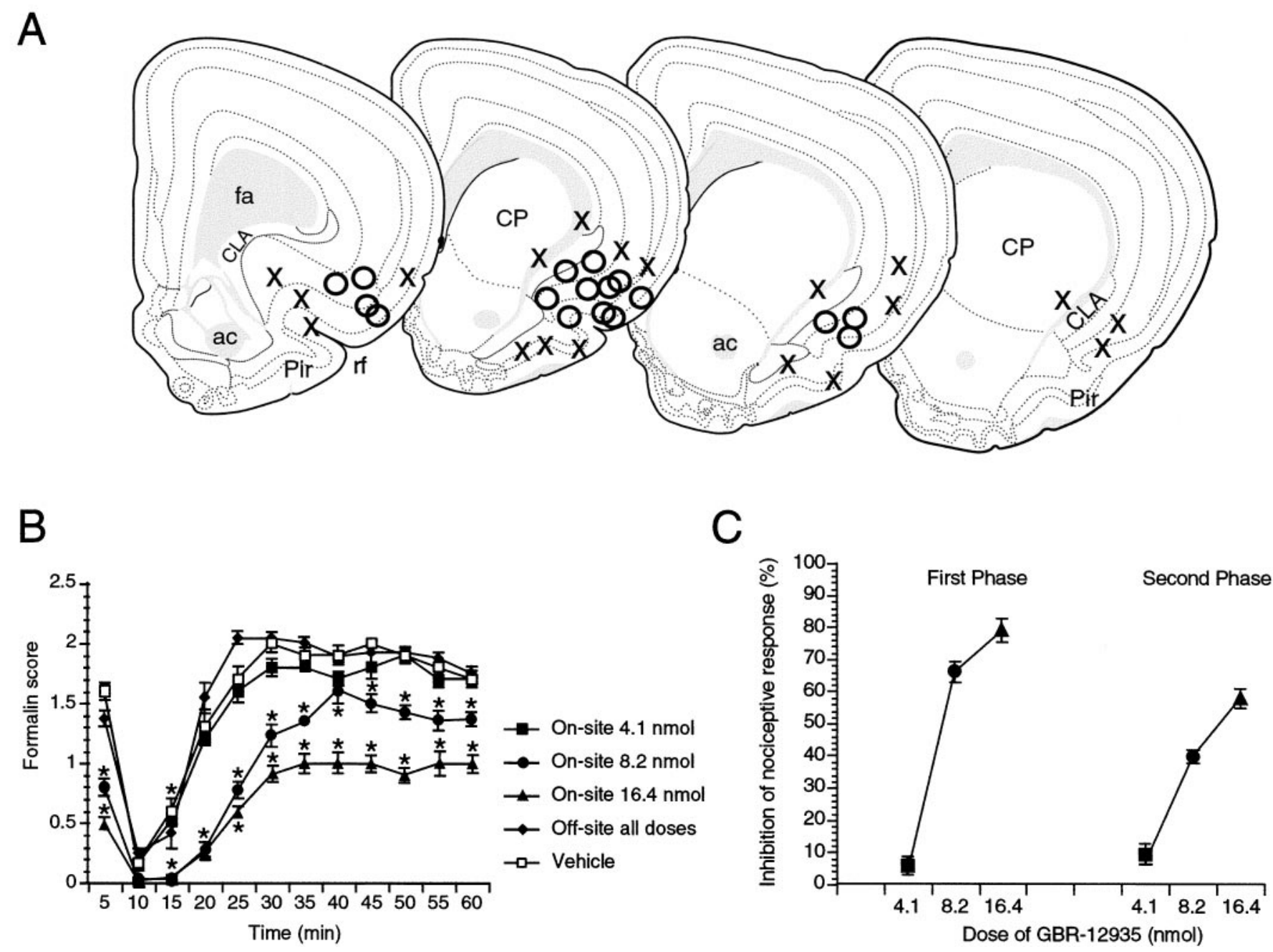

Figure 3. A, Mapping of representative injection sites of $8.2 \mathrm{nmol}$ of GBR-12935 administered before a formalin stimulus (50 $\mu$ l of formalin $2 \%$ ). Open circles mark the injection sites of rats displaying antinociception, whereas $X$ marks sites where the drug had no significant effect on the formalin behavior. From left (rostral) to right (caudal) the sections correspond to levels $+2.80,+2.15$, and +1.70 and +1.45 of Swanson's atlas. Note that on the caudal section on the far right, corresponding to a level of +1.45 of Swanson's atlas, no effect of GBR-12935 was observed. $B$, Formalin, behavioral scores over time. Because scores of off-site-injected rats did not differ for different GBR-12935 doses, they are presented as a single group. $C$, Dose-response curves of the antinociceptive effect of GBR-12935 in the first phase (0-10 min after stimulus) and second phase (11-60 min after stimulus) of the formalin test. Percentage of inhibition $=[1-($ average score drug-treated/average score saline-treated $)] \times 100$. Error bars denote the SEM. * Significant difference $(p<0.05)$ from vehicle-treated animals. $a c$, Anterior commissure; $C L A$, claustrum; $C P$, caudate-putamen; $f a$, anterior forceps of the corpus callosum; Pir, piriform cortex; $r f$, rhinal fissure.

strated a significant $(p<0.01)$ reduction in the number of Fos-immunolabled neurons (Figs. 4, 5). For the latter, the relative decrease in the number of Fos-immunoreactive cells was $26 \pm$ $6.2 \%$ in the superficial dorsal horn, $53 \pm 8.5 \%$ in the neck of the dorsal horn, and $43 \pm 12 \%$ in the central canal area. Off-site GBR-12935 resulted in no significant difference in the number of Fos-immunoreactive cells from vehicle controls $(p>0.05)$.

Electrophysiological recording of nociceptive response activity in the lumbar dorsal horn after GBR-12935 microinjection in the $R A I C$

Recordings were made from 12 lumbar WDR-type dorsal horn neurons in 10 rats. The units were located $455.2 \pm 218.5 \mu \mathrm{m}$ below the surface of the spinal cord in a region corresponding to laminae IV and V of the dorsal horn. All recordings were performed contralateral to the injection of GBR-12935 (8.2 nmol/400 nl). Post hoc histological analysis revealed that 10 on-site (in the RAIC) and 15 off-site injections were made. For the on-site injections, a significant reduction (to a mean of $34 \%$ of baseline; $p<0.05)$ in neuronal nociceptive heat-evoked responses occurred on average 12 min after drug injection (Fig. 6). In three cases, further microinjection of the selective D1 antagonist SCH$23390(12 \mathrm{nmol} / 400 \mathrm{nl})$ in the RAIC reversed the effect of the dopamine reuptake inhibitor (Fig. 7).

\section{Pronociceptive effect of SCH-23390 in the RAIC}

To test for an antinociceptive effect of basal dopamine receptor stimulation in the RAIC, the D1 dopamine receptor antagonist SCH-23390 (0.24, 1.2, $6.0 \mathrm{nmol})$ was administered locally, and withdrawal latencies from a nociceptive heat stimulus as well as ability to stay on the rotarod were assessed. Because the formalin test does not permit multiple trials in the same animal to assess nociceptive responses at rest and does not allow the combining of nociceptive and motor testing, we chose the paw heat-withdrawal test for this set of experiments. Changes in paw withdrawal latency to heat thereby could be directly correlated with motor 


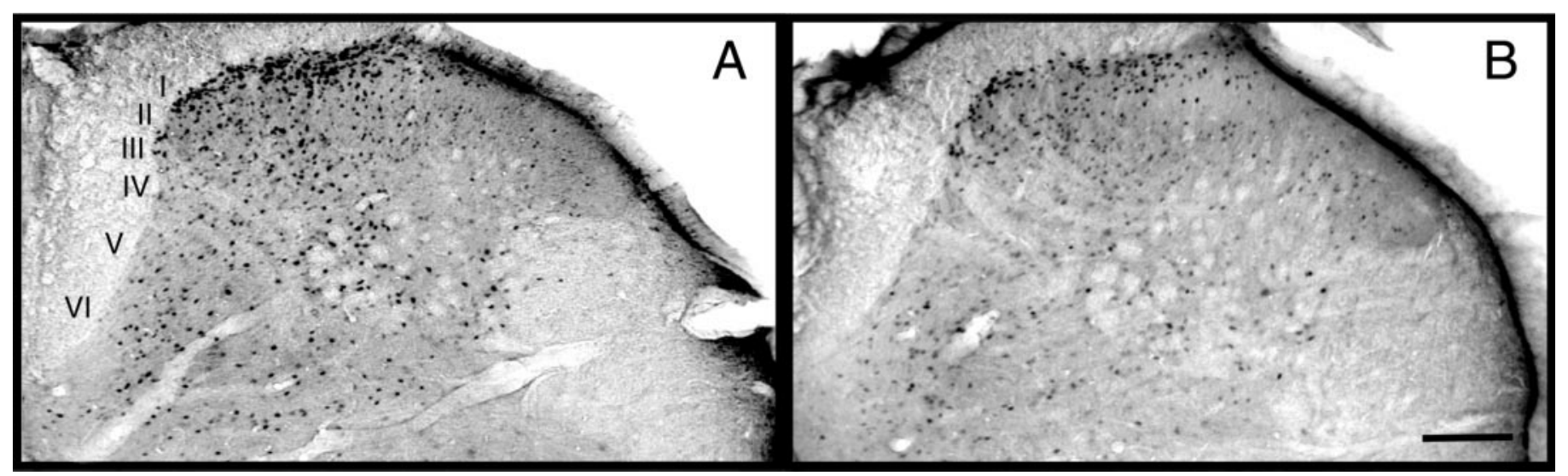

Figure 4. Fos-like immunoreactive cells in the lumbar dorsal horn (L4-5) after hindpaw formalin testing in rats injected with GBR-12935 in the ipsilateral RAIC. $A$, Rat injected off-site exhibiting no antinociception. $B$, Rat injected on-site and exhibiting antinociception. In the spinal cord of the on-site-injected rat, there is markedly less stimulus-induced expression of $c$-fos compared with the off-site-injected rat $(p<0.05)$. Laminae I-VI of the dorsal horn are indicated in $A$. Scale bar, $150 \mu \mathrm{m}$.

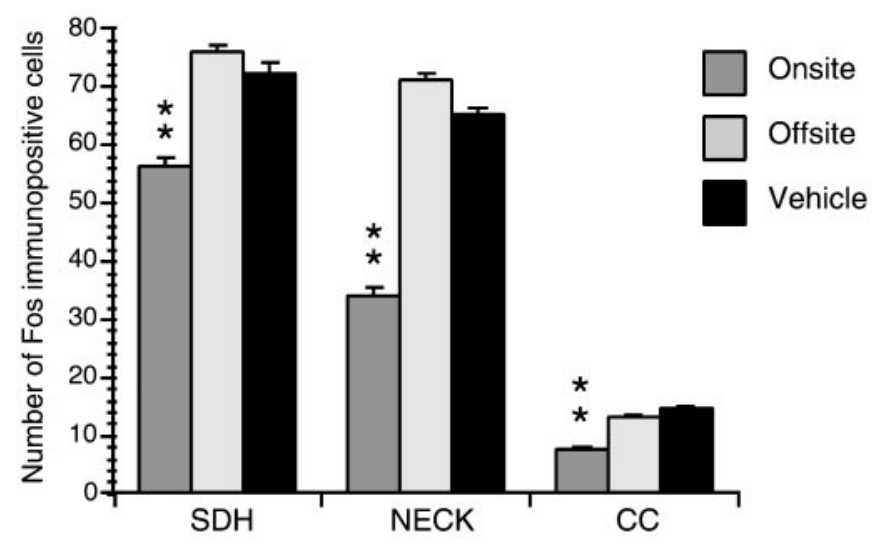

Figure 5. Average number of Fos-immunopositive cells counted in nociceptive areas of the L4 -5 spinal levels $1 \mathrm{hr}$ after formalin injection in the ipsilateral hindpaw. Fos counts in rats injected with GBR-12935 in the RAIC (on-site) were significantly lower than those injected with vehicle or in brain areas surrounding the RAIC (off-site) $\left({ }^{* *} p<0.01\right) . S D H$, Superficial dorsal horn (i.e., lamina I and outer lamina II); $N E C K$, neck of the dorsal horn (laminae IV-VI); $C C$, central canal area.

function, each animal serving as its own control. This strategy also allowed us to minimize the number of experimental animals. Of note, in addition to the observed changes in paw withdrawal latency, animals injected on-site with SCH-23390 often vocalized when manipulated or when their fur was gently brushed, a behavior suggestive of mechanical allodynia. After histological analysis of the cannula tracts, SCH-23390-treated rats were assigned to the on-site or off-site groups; the vehicle-treated group was not subdivided according to the injection site. Comparison of the paw withdrawal latencies for the three groups (on-site, off-site, vehicle) was performed for the average score over the entire testing period and also for each testing time point (Table 1, Fig. 8). For the on-site group, significance was considered for values different $(p<0.05)$ from those of both the off-site and vehicle-treated groups. The lowest dose of SCH-23390 (0.24 nmol, on-site: $n=8$; off-site: $n=4$; saline: $n=4$ ) had no significant effect ( $p>0.05)$, although when comparing individual on-site cases with the mean of the two other groups, half of these animals had a significantly lower average score. At the intermediate doses of SCH-23390 (1.2 nmol, on-site: $n=6$; off-site: $n=5$; saline: $n=4$ ), significant

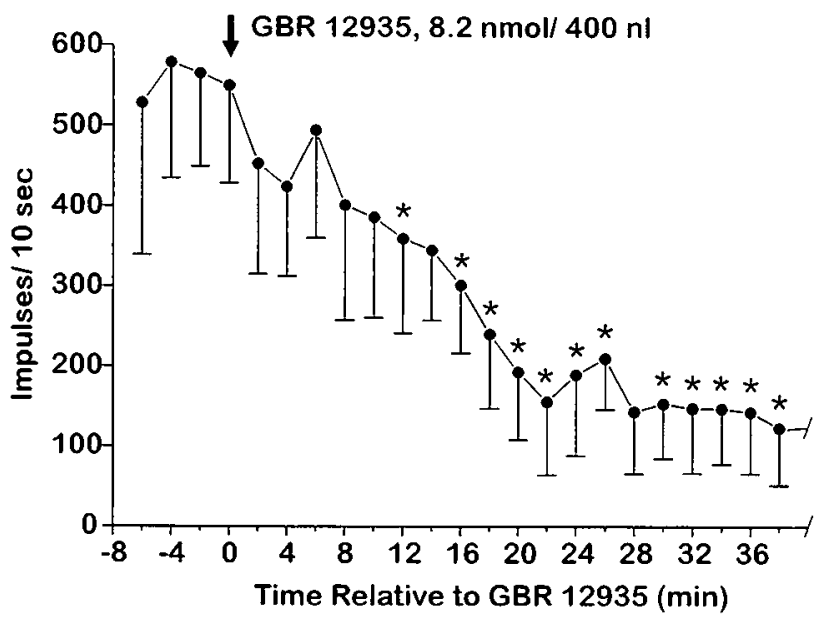

Figure 6. Depression of nociceptive responses of spinal WDR units by injection of the dopamine reuptake inhibitor GBR 12935 into RAIC. Graph plots mean responses of 10 WDR units versus time relative to injection of GBR 12935 on-site. Error bars represent SEM. * Significantly different from mean preinjection baseline ( $p<0.05, t$ test).

decreases $(p<0.05)$ in withdrawal latency were found bilaterally for on-site injections only (Fig. 8). Vehicle and off-site controls differed at one time point only for each paw. At the highest dose of SCH-23390 (6.0 nmol, on-site: $n=5$; off-site: $n=9$; saline: $n=$ $4)$, significant increases $(p<0.05)$ in withdrawal latencies were found for both ipsilateral and contralateral injections at different time points over the entire testing period. Because of the finding of a motor impairment at this high dose of the D1 antagonist, no conclusion could be made on the results of nociceptive behavioral testing. No significant motor impairment was found at the lowest and middle doses ( 0.24 and $1.2 \mathrm{nmol} \mathrm{SCH}-23390)$ between on-site or off-site groups and vehicle controls $(p>0.05)$.

Immediately after completion of thermal paw withdrawal testing (45 min after drug injection), the animals reported above were tested on the accelerating rotarod apparatus to assess motor function (Table 2). Animals demonstrated the ability in pretest training to remain on the apparatus until the $300 \mathrm{sec}$ cutoff throughout a series of six trials. Although no significant motor impairment was found at the lowest and middle doses $(0.24$ and $1.2 \mathrm{nmol} \mathrm{SCH}-23390)$ compared with saline controls $(p>0.05)$, 

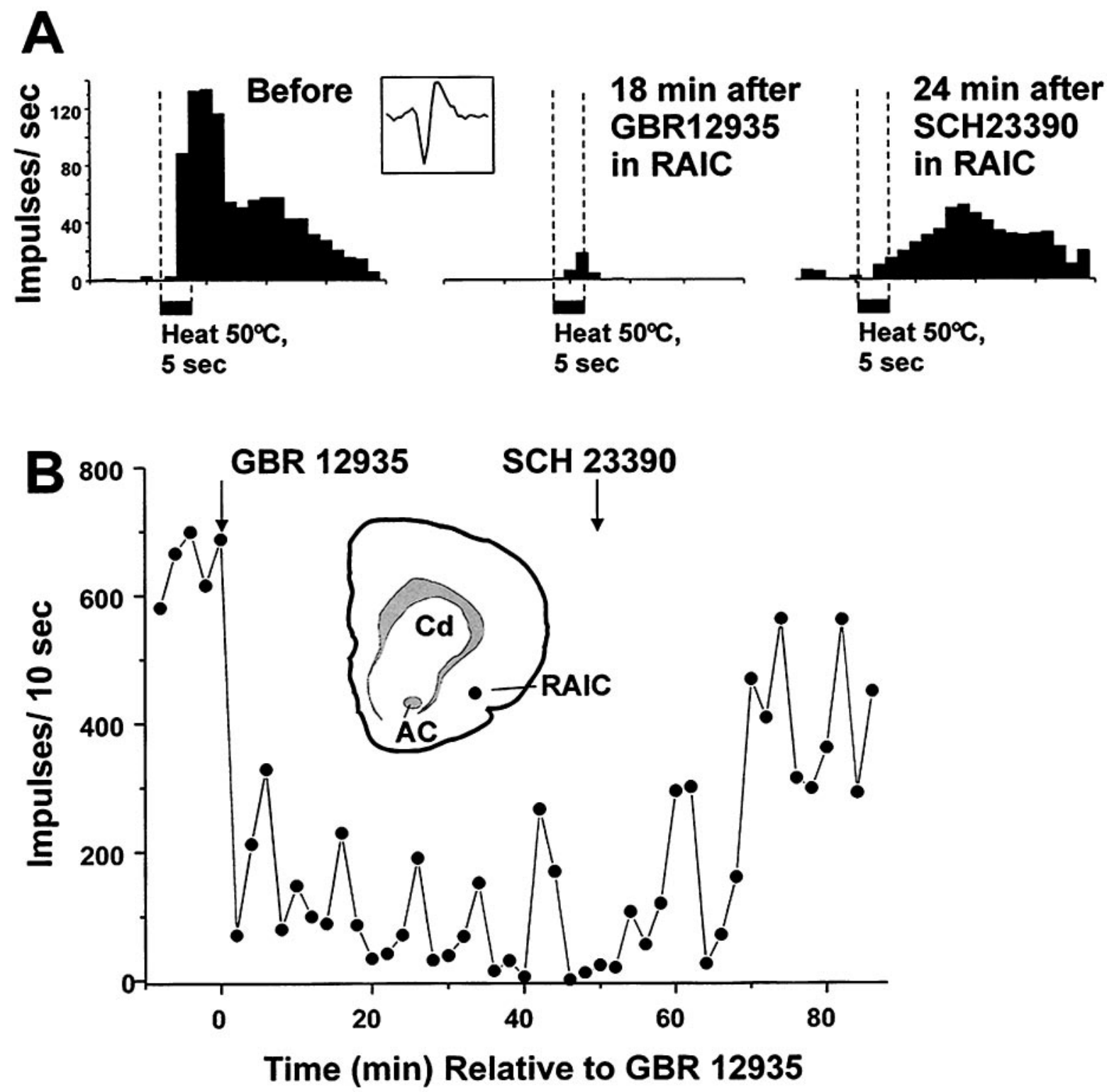

Figure 7. Example showing depression of nociceptive responses of a single spinal WDR unit after microinjection of the dopamine reuptake inhibitor GBR 12935 into the RAIC. A, PSTH (bin width, $1 \mathrm{sec}$ ) of unit's response to $50^{\circ} \mathrm{C}$ noxious heat stimuli, before (left $\mathrm{PSTH}$ ) and $18 \mathrm{~min}$ after (middle PSTH) injection of GBR 12935 into RAIC. Right PSTH shows partial recovery of unit response 24 min after microinjection of the D1 receptor antagonist $\mathrm{SCH}-23390$ at the same site in the RAIC. Inset shows representative sample of unit action potential. $B$, Graph plots responses of unit shown in $A$ versus time relative to GBR 12935 (injected at first arrow). Time of injection of SCH-23390 is indicated by second arrow. Inset shows drawing of brain section containing RAIC injection site $(d o t)$. $A C$, Anterior commissure; $C d$, caudate nucleus; $R A I C$, rostral agranular insular cortex.

motor impairment was detected for the highest dose of SCH23390 ( $6.0 \mathrm{nmol})$. On-site, off-site, and vehicle controls all differed significantly from each other $(p<0.05)$.

\section{DISCUSSION}

\section{Role of dopamine in antinociception}

The present study provides evidence implicating dopaminergic neurotransmission in the cortical modulation of nociceptive behavior, as local increases of endogenous dopamine in the RAIC produced sustained antinociception. This appears to involve activation of descending antinociceptive systems, leading to an inhibition of spinal nociceptive neurons, an effect that would be partly mediated through D1 receptors at the level of the cortex.

In the rat, dopamine-mediated antinociception has been re- ported in many studies (Carr, 1984; Tricklebank et al., 1984; Morgan and Franklin, 1991; Liu et al., 1992; Altier and Stewart, 1993, 1998; Kiritsy-Roy et al., 1994; Saadé et al., 1997). Dopaminergic neurons of the VTA in particular are involved in both endogenous and morphine-induced antinociception (Altier and Stewart, 1993, 1996, 1997; Devine et al., 1993; Saadé et al., 1997). This may occur through increased release of dopamine in VTA neuron projection areas, including the medial prefrontal cortex, nucleus accumbens, medial striatum, and RAIC. Depleting, antagonizing, or increasing dopamine release in these areas affects nociceptive responses, suggesting that dopamine acts both phasically and tonically on nociceptive neural circuits (Altier and Stewart, 1993, 1998; Saadé et al., 1997). In the RAIC, increasing extracellular dopamine activates descending antinociceptive cir- 


\begin{tabular}{|c|c|c|c|c|c|c|}
\hline \multirow[b]{2}{*}{ Dose of SCH-23390 } & \multicolumn{2}{|c|}{ Onsite } & \multicolumn{2}{|c|}{ Offsite } & \multicolumn{2}{|c|}{ Vehicle } \\
\hline & $n$ & Average time (sec) & $n$ & Average time (sec) & $n$ & Average time (sec) \\
\hline \multicolumn{7}{|l|}{$0.24 \mathrm{nmol}$} \\
\hline ipsilateral & 8 & $3.2 \pm 0.03$ & 4 & $3.3 \pm 0.03$ & 4 & $3.3 \pm 0.03$ \\
\hline contralateral & & $3.2 \pm 0.02$ & & $3.3 \pm 0.05$ & & $3.3 \pm 0.02$ \\
\hline \multicolumn{7}{|l|}{$1.2 \mathrm{nmol}$} \\
\hline ipsilateral & 6 & $3.2 \pm 0.01$ & 5 & $3.6 \pm 0.01$ & 4 & $3.6 \pm 0.06$ \\
\hline contralateral & & $3.1 \pm 0.07^{*}$ & & $3.5 \pm 0.02$ & & $3.5 \pm 0.04$ \\
\hline \multicolumn{7}{|l|}{$6.0 \mathrm{nmol}$} \\
\hline ipsilateral & 5 & $4.8 \pm 0.2$ & 9 & $4.2 \pm 0.06$ & 4 & $3.8 \pm 0.2$ \\
\hline contralateral & & $5.5 \pm 0.2 *$ & & $4.4 \pm 0.06$ & & $3.7 \pm 0.04$ \\
\hline
\end{tabular}

* Significantly different from both offsite and vehicle injected on the same side $(p<0.05)$.

cuits, as suggested here by the observation that local administration of GBR-12935 blocks noxious stimulus-evoked activation of WDR dorsal horn neurons and $c$-fos expression in nociceptive areas of the spinal cord. Because other forebrain areas where dopaminergic VTA neurons project, such as the prefrontal cortex and nucleus accumbens, have been implicated in nociceptive inhibition (Hardy, 1985; Hardy and Haigler, 1985; Yu and Han, 1990; Gear and Levine, 1995), it is also possible that these areas share with the RAIC common mechanisms through which dopamine produces antinociception in addition to affecting mood (King et al., 1997). Importantly, many of the basal forebrain areas receiving dopaminergic afferents (Deutch et al., 1988; Domesick, 1988) have, like the RAIC, been implicated in systemic morphine antinociception (Yaksh et al., 1976, 1977; Rodgers, 1977; Li and Xu, 1990; Jones et al., 1991; Ma and Han, 1991; Helmstetter et al., 1993; Manning and Mayer, 1995; Manning and Franklin, 1998; Pavlovic and Bodnar, 1998).

Our observation that microinjection of a dopamine reuptake inhibitor into the RAIC significantly reduced the number of dorsal horn neurons expressing $c$-fos provides further support that dopamine in the RAIC recruits a descending spinal inhibitory pathway. The immediate early gene $c$-fos is used as an indicator of neural activity of spinal neurons, and the topographical distribution of cells with an increased expression is related to the type of stimulus, i.e., noxious versus innocuous (Hunt et al., 1987; Jasmin et al., 1994). Given that the present $c$-fos protocol tested only a noxious stimulus, we cannot conclude that this descending inhibition was limited to nociceptive transmission. Because none of the animals displayed motor deficits up to the intermediate drug doses, the inhibition of nociceptive behavior was unlikely caused by motor impairment. In addition, the results of the electrophysiological experiments provide further evidence for dopamine activation of descending antinociceptive inhibitory mechanisms (Kiritsy-Roy et al., 1994) and suggest that dopamine and morphine in the RAIC produce antinociception through the same neural circuits (Burkey et al., 1996).

Mapping of cannulae tracts demonstrated that the site where the dopamine-acting drugs are effective is localized to the RAIC. This localized effect of the dopamine reuptake inhibitor and the D1 receptor antagonist on nociceptive behavior or activity of spinal nociceptive neurons extends our previous demonstration of a site-specific effect of morphine and naloxone in the RAIC (Burkey et al., 1996). Although in general the effects of both drugs used in the present study appeared to be more marked for injections in the inner laminae, consistent with the highest con- centrations of dopaminergic fibers and the location of most dopaminergic receptors (Gaspar et al., 1995), this pattern was not observed in all animals; therefore we could not conclude that the drug effect is limited to specific laminae.

We cannot rule out the possibility that increases in local noradrenaline, whether stimulus induced (Mantz et al., 1988; Tanaka et al., 1991) or induced by the dopamine reuptake inhibitor or both, contribute to the effect of dopamine in the RAIC, because both neurotransmitters are required for RAIC modulation of heart rate (Funk and Stewart, 1996). Although previous studies have found that the reuptake inhibitor GBR-12935 acts predominantly on the dopamine transporter with little effect on the other monoamine transporters (Graham and Langer, 1992; Chen and Reith, 1994; Matecka et al., 1996), there is a slight but significant increase in serotonin and noradrenaline measured by in vivo microdialysis in the VTA when GBR-12935 is given systemically (Reith et al., 1997).

\section{Tonic dopamine antinociception}

The modulation of heat-induced paw withdrawal by the D1 receptor antagonist in the RAIC suggests that dopamine receptors in the cerebral cortex could exert a tonic inhibition on nociceptive responses. The shift from decreased to increased withdrawal latencies at the highest dose of the antagonist $(6 \mathrm{nmol})$ cannot be interpreted because of the appearance of motor impairment for the on-site injections. This motor impairment could result from a diff usion of the antagonist to the caudate-putamen. In the off-site cases, absence of motor impairment likely results from the location of most injections farther away from the caudate-putamen. In support of such a hypothesis, when we used a higher dose of SCH-23390 (12 nmol), which could allow higher drug concentrations to reach the caudate-putamen from off-site injections, we observed motor impairment in all animals (data not shown). Alternately, because motor responses have been evoked from microstimulation of the RAIC, but not from the insular cortex lying dorsal to it (Neafsey et al., 1986), the observed motor impairment might result from local effects of the antagonist perturbing motor function.

\section{Functional interactions of dopamine and opioid systems in the RAIC}

It is possible that in the RAIC opioid and dopamine systems interact in a manner that regulates cortical neuronal output and, through yet undefined connections, nociceptive thresholds. This interaction is presumably different from the one described in the 


\section{$\mathrm{SCH}-233900.24 \mathrm{nmol}$}
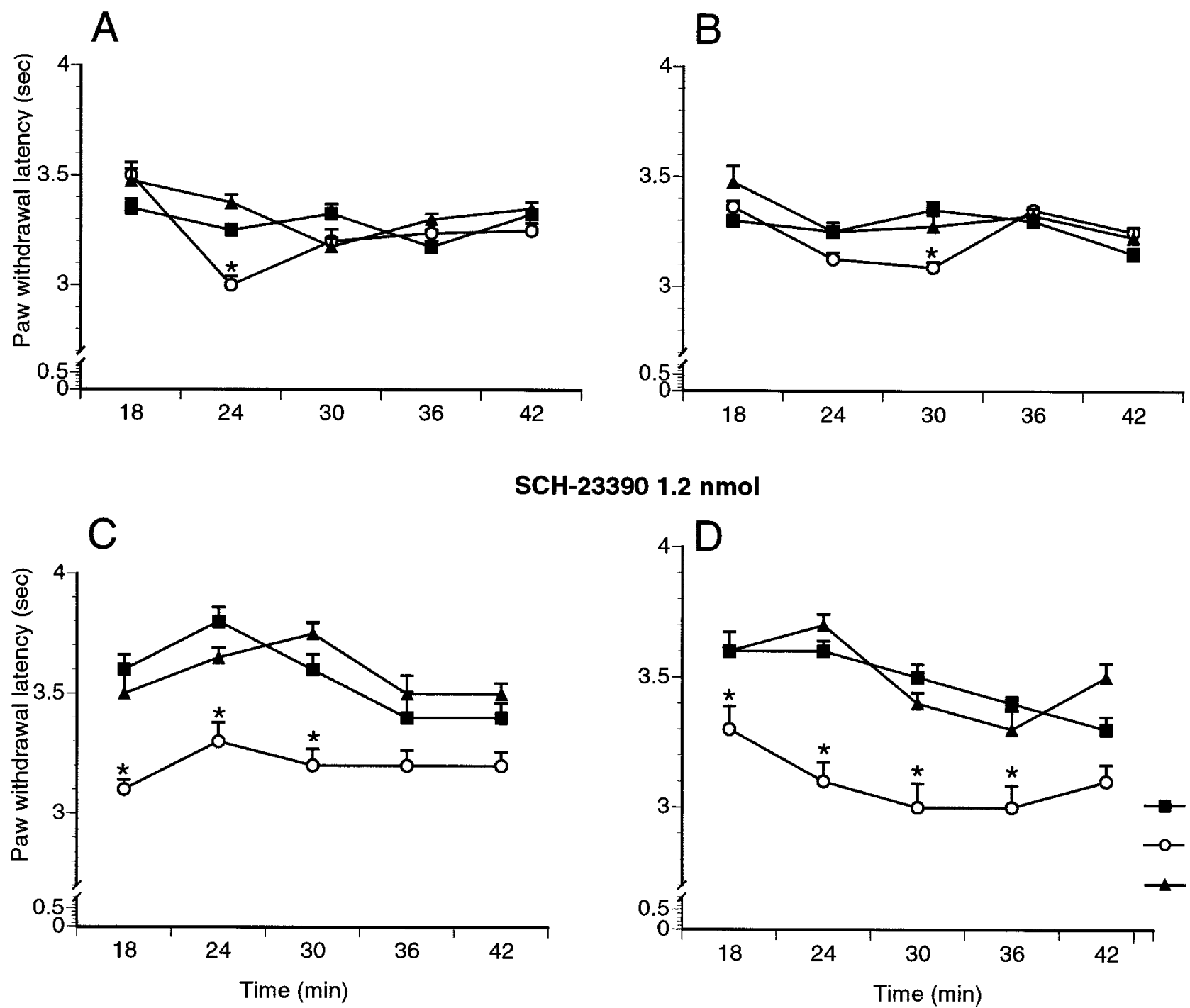

IPSILATERAL HINDPAW

$\mathrm{SCH}-233901.2 \mathrm{nmol}$

Figure 8. Withdrawal latencies to a nociceptive thermal stimulus of the hindpaw 15 min after injection of the D1 receptor antagonist SCH-23390 in the RAIC (on-site) or in the cortex surrounding the RAIC (off-site). At the lowest dose ( $0.24 \mathrm{nmol})$, slight hyperalgesia is detected for the on-site group at 24 and $30 \mathrm{~min}$ (ipsilateral and contralateral paw, respectively). At the middle dose (1.2 nmol), sustained hyperalgesia is observed in the on-site group until 30 min. ${ }^{*} p<0.05$.

Table 2. Average time spent on the rotarod after $\mathrm{SCH}-23390$ in the RAIC

\begin{tabular}{llllll} 
& \multicolumn{2}{l}{ Onsite } & & \multicolumn{2}{l}{ Offsite } \\
\cline { 2 - 3 } Dose of SCH-23390 & $n$ & Average time $(\mathrm{sec})$ & & & Average time $(\mathrm{sec})$ \\
\hline $0.24 \mathrm{nmol}$ & 8 & $300 \pm 1$ & & 4 & $300 \pm 1$ \\
$1.2 \mathrm{nmol}$ & 6 & $300 \pm 6$ & & 5 & $300 \pm 2$ \\
$6.0 \mathrm{nmol}$ & 5 & $13 \pm 3^{*}$ & & 9 & $198 \pm 14^{*}$ \\
Vehicle & 5 & $300 \pm 1$ & & 7 & $300 \pm 2$
\end{tabular}

* Significantly different from vehicle injected on the same side $(p<0.05)$.

ventral tegmental areas where morphine increases the release of dopamine by inhibiting GABAergic interneurons (Johnson and North, 1992), because application of the $\mathrm{GABA}_{\mathrm{A}}$ antagonist bicuculline in the RAIC has no antinociceptive effect (L. Jasmin

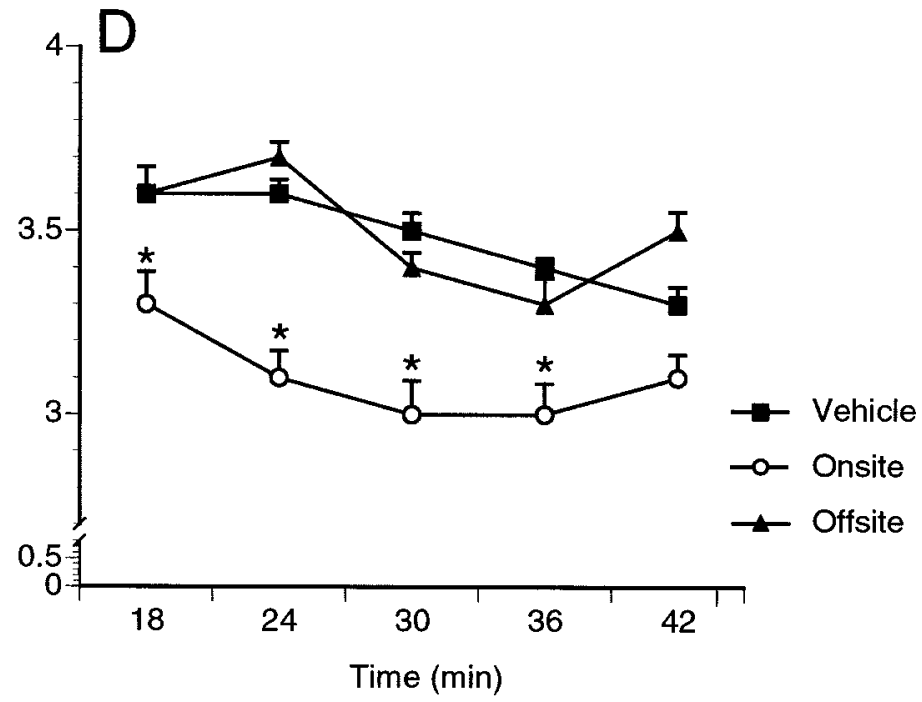

CONTRALATERAL HINDPAW and A. Burkey, unpublished observation). Because both $\mu$-opioid and dopamine receptors are present postsynaptically in the RAIC (al-Tikriti et al., 1992; Gaspar et al., 1995; Burkey et al., 1996), it is possible that both opiates and dopamine directly inhibit cortical output neurons. This would be analogous to the medial prefrontal cortex where dopaminergic afferents block output neuron activity without affecting afferent input (Thierry et al., 1998).

Our physiological recordings of WDR neurons in the neck of the lumbar dorsal horn confirmed the inhibition of noxiousevoked increased activity implied by the results of Fos immunocytochemistry. This is similar to our findings with morphine (Burkey et al., 1996). The average time required for SCH-23390 to produce reversal of dopaminergic descending inhibition (12 $\mathrm{min}$ ) is comparable to the time required for naloxone to reverse morphine-induced descending inhibition from the RAIC (Burkey 
et al., 1996). In the case of SCH-23390, this could correspond to a delay for the drug to bind to a sufficient fraction of the D1 receptors to produce an effect (McQuade et al., 1991). Another possibility is that both dopamine and opiates acting in the RAIC invoke an ancillary system whose descending inhibitory activity continues for some time after receptor blockade. This system could involve the midbrain periaqueductal gray matter, where a brief electrical stimulus induces a sustained descending antinociception that persists for up to 20 min (Mayer and Liebeskind, 1974; Cahusac et al., 1995).

\section{Conclusion}

The originality of the present study is the demonstration of a dopaminergic modulation of nociception from a localized cortical area. Previous studies have reported a role of dopaminergic systems in nociception with systemic agonist or antagonist, but the effects were often mixed. For instance, systemic administration of levodopa, the dopamine precursor molecule, produces dose-dependent pronociception and antinociception in the same animal over $90 \mathrm{~min}$ (Paalzow, 1992). Given that the dopaminergic system is functionally highly compartmentalized, the site specificity in the present study likely reflects a functional specialization of the RAIC. Still, the RAIC is not the only site where dopamine affects nociception, because increasing the release of dopamine in nucleus accumbens is also antinociceptive on the formalin test through both D1 and D2 receptors (Altier and Stewart, 1993). Because the RAIC and nucleus accumbens are interconnected with other areas of the ventral forebrain where dopamine neurotransmission is prevalent, such as the prefrontal cortex (Oades and Halliday, 1987; Deutch et al., 1988; Mantz et al., 1989; Conde et al., 1995; Montaron et al., 1996), future studies could investigate whether the effect of dopamine on nociception results from a combined effect on these interconnected areas.

\section{REFERENCES}

Akil M, Lewis DA (1993) The dopaminergic innervation of monkey entorhinal cortex. Cereb Cortex 3:533-550.

al-Tikriti MS, Roth RH, Kessler RM, Innis RB (1992) Autoradiographic localization of dopamine D1 and D2 receptors in rat cerebral cortex following unilateral neurotoxic lesions. Brain Res 575:39-46.

Altier N, Stewart J (1993) Intra-VTA infusions of the substance P analogue, DiMe-C7, and intra-accumbens infusions of amphetamine induce analgesia in the formalin test for tonic pain. Brain Res 628:279-285.

Altier N, Stewart J (1996) Opioid receptors in the ventral tegmental area contribute to stress-induced analgesia in the formalin test for tonic pain. Brain Res 718:203-206.

Altier N, Stewart J (1997) Tachykinin NK-1 and NK-3 selective agonists induce analgesia in the formalin test for tonic pain following intra-VTA or intra-accumbens microinfusions. Behav Brain Res 89:151-165.

Altier N, Stewart J (1998) Dopamine receptor antagonists in the nucleus accumbens attenuate analgesia induced by ventral tegmental area substance $\mathrm{P}$ or morphine and by nucleus accumbens amphetamine. J Pharmacol Exp Ther 285:208-215.

Backonja M, Miletic V (1991) Responses of neurons in the rat ventrolateral orbital cortex to phasic and tonic nociceptive stimulation. Brain Res 557:353-355.

Backonja M, Wang B, Miletic V (1994) Responses of neurons in the ventrolateral orbital cortex to noxious cutaneous stimulation in a rat model of peripheral mononeuropathy. Brain Res 639:337-340.

Burkey AR, Carstens E, Wenniger JJ, Tang JW, Jasmin L (1996) An opioidergic cortical antinociception triggering site in the agranular insular cortex of the rat that contributes to morphine antinociception. J Neurosci 16:6612-6623.

Cahusac PM, Morris R, Hill RG (1995) A pharmacological study of the modulation of neuronal and behavioural nociceptive responses in the rat trigeminal region. Brain Res 700:70-82.
Carr KD (1984) Dopaminergic mechanisms in the supraspinal modulation of pain. Pain [Suppl] 2:S223.

Cenci MA, Kalen P, Mandel RJ, Bjorklund A (1992) Regional differences in the regulation of dopamine and noradrenaline release in medial frontal cortex, nucleus accumbens and caudate-putamen: a microdialysis study in the rat. Brain Res 581:217-228.

Chen NH, Reith ME (1994) Effects of locally applied cocaine, lidocaine, and various uptake blockers on monoamine transmission in the ventral tegmental area of freely moving rats: a microdialysis study on monoamine interrelationships. J Neurochem 63:1701-1713.

Clavier RM, Gerfen CR (1979) Self-stimulation of the sulcal prefrontal cortex in the rat: direct evidence for ascending dopaminergic mediation. Neurosci Lett 12:183-187.

Conde F, Maire-Lepoivre E, Audinat E, Crepel F (1995) Afferent connections of the medial frontal cortex of the rat. II. Cortical and subcortical afferents. J Comp Neurol 352:567-593.

Descarries L, Lemay B, Doucet G, Berger B (1987) Regional and laminar density of the dopamine innervation in adult rat cerebral cortex. Neuroscience 21:807-824.

Deutch AY, Goldstein M, Baldino Jr F, Roth RH (1988) Telencephalic projections of the A8 dopamine cell group. Ann NY Acad Sci 537:27-50.

Devine DP, Leone P, Pocock D, Wise RA (1993) Differential involvement of ventral tegmental mu, delta and kappa opioid receptors in modulation of basal mesolimbic dopamine release: in vivo microdialysis studies. J Pharmacol Exp Ther 266:1236-1246.

Divac I, Kosmal A, Björklund A, Lindvall O (1978) Subcortical projections to the prefrontal cortex in the rat as revealed by the horseradish peroxidase technique. Neuroscience 3:785-796.

Domesick VB (1988) Neuroanatomical organization of dopamine neurons in the ventral tegmental area. Ann NY Acad Sci 537:10-26.

Dubuisson D, Dennis SG (1977) The formalin test: a quantitative study of the analgesic effects of morphine, meperidine, and brainstem stimulation in rats and cats. Pain 4:161-174.

Forster C, Handwerker HO (1990) Automatic classification and analysis of microneurographic spike data using a PC/AT. J Neurosci Methods 31:109-118.

Funk D, Stewart J (1996) Role of catecholamines in the frontal cortex in the modulation of basal and stress-induced autonomic output in rats. Brain Res 741:220-229.

Gaspar P, Bloch B, Le Moine C (1995) D1 and D2 receptor gene expression in the rat frontal cortex: cellular localization in different classes of efferent neurons. Eur J Neurosci 7:1050-1063.

Gear RW, Levine JD (1995) Antinociception produced by an ascending spino-supraspinal pathway. J Neurosci 15:3154-3161.

Goldman-Rakic PS (1998) The cortical dopamine system: role in memory and cognition. Adv Pharmacol 42:707-711.

Graham D, Langer SZ (1992) Advances in sodium-ion coupled biogenic amine transporters. Life Sci 51:631-645.

Hardy SG (1985) Analgesia elicited by prefrontal stimulation. Brain Res 339:281-284.

Hardy SG, Haigler HJ (1985) Prefrontal influences upon the midbrain: a possible route for pain modulation. Brain Res 339:285-293.

Helmstetter FJ, Bellgowan PS, Tershner SA (1993) Inhibition of the tail flick reflex following microinjection of morphine into the amygdala. NeuroReport 4:471-474.

Hunt SP, Pini A, Evan G (1987) Induction of c-fos-like protein in spinal cord neurons following sensory stimulation. Nature 328:632-634.

Jasmin L, Gogas KR, Ahlgren SC, Levine JD, Basbaum AI (1994) Walking evokes a distinctive pattern of Fos-like immunoreactivity in the caudal brainstem and spinal cord of the rat. Neuroscience $58: 275-286$

Jasmin L, Kohan L, Franssen M, Janni G, Goff JR (1998) The cold plate as a test of nociceptive behaviors: description and application to the study of chronic neuropathic and inflammatory pain models. Pain 75:367-382.

Johnson S, North R (1992) Opioids excite dopamine neurons by hyperpolarization of local interneurons. J Neurosci 12:483-488.

Jones AK, Friston KJ, Qi LY, Harris M, Cunningham VJ, Jones T, Feinman C, Frackowiak RS (1991) Sites of action of morphine in the brain. Lancet 338:825.

Jones MW, Kilpatrick IC, Phillipson OT (1986) The agranular insular cortex: a site of unusually high dopamine utilisation. Neurosci Lett 72:330-334.

King D, Zigmond MJ, Finlay JM (1997) Effects of dopamine depletion 
in the medial prefrontal cortex on the stress-induced increase in extracellular dopamine in the nucleus accumbens core and shell. Neuroscience 77:141-153.

Kiritsy-Roy JA, Shyu BC, Danneman PJ, Morrow TJ, Belczynski C, Casey KL (1994) Spinal antinociception mediated by a cocainesensitive dopaminergic supraspinal mechanism. Brain Res 644:109-116.

Larisch R, Klimke A, Vosberg H, Loffler S, Gaebel W, Muller-Gartner HW (1997) In vivo evidence for the involvement of dopamine-D2 receptors in striatum and anterior cingulate gyrus in major depression. NeuroImage 5:251-260.

Li BY, Xu T (1990) Influence of morphine microinjected into head of caudate nucleus on electric activities of nociceptive neurons in parafascicular nucleus of rat thalamus. Chung Kuo Yao Li Hsueh Pao 11:103-107.

Liu QS, Qiao JT, Dafny N (1992) D2 dopamine receptor involvement in spinal dopamine-produced antinociception. Life Sci 51:1485-1492.

Llewellyn-Smith IJ, Minson JB (1992) Complete penetration of antibodies into vibratome sections after glutaraldehyde fixation and ethanol treatment: light and electron microscopy for neuropeptides. J Histochem Cytochem 40:1741-1749.

Ma QP, Han JS (1991) Neurochemical studies on the mesolimbic circuitry of antinociception. Brain Res 566:95-102.

Main DC, Waterman AE, Kilpatrick IC (1995) Behavioural analysis of changes in nociceptive thresholds produced by remoxipride in sheep and rats. Eur J Pharmacol 287:221-231.

Manning BH, Franklin KB (1998) Morphine analgesia in the formalin test: reversal by microinjection of quaternary naloxone into the posterior hypothalamic area or periaqueductal gray. Behav Brain Res 92:97-102.

Manning BH, Mayer DJ (1995) The central nucleus of the amygdala contributes to the production of morphine antinociception in the formalin test. Pain 63:141-152.

Mantz J, Milla C, Glowinski J, Thierry AM (1988) Differential effects of ascending neurons containing dopamine and noradrenaline in the control of spontaneous activity and of evoked responses in the rat prefrontal cortex. Neuroscience 27:517-526.

Mantz J, Thierry AM, Glowinski J (1989) Effect of noxious tail pinch on the discharge rate of mesocortical and mesolimbic dopamine neurons: selective activation of the mesocortical system. Brain Res 476:377-381.

Matecka D, Rothman RB, Radesca L, de Costa BR, Dersch CM, Partilla JS, Pert A, Glowa JR, Wojnicki FH, Rice KC (1996) Development of novel, potent, and selective dopamine reuptake inhibitors through alteration of the piperazine ring of 1-[2- (diphenylmethoxy)ethyl]- and 1-[2-[bis(4-fluorophenyl)methoxy]ethyl]-4-(3-phenylpropyl)piperazines (GBR 12935 and GBR 12909). J Med Chem 39:4704-4716.

Mayer DJ, Liebeskind JC (1974) Pain reduction by focal electrical stimulation of the brain: an anatomical and behavioral analysis. Brain Res 68:73-93.

McQuade RD, Duffy RA, Anderson CC, Crosby G, Coffin VL, Chipkin RE, Barnett A (1991) [3H]SCH 39166, a new D1-selective radioligand: in vitro and in vivo binding analyses. J Neurochem 57:2001-2010.

Menétrey D (1987) Spinal nociceptive neurons at the origin of long ascending pathways in the rat: electrophysiological, anatomical and immunohistochemical approaches. In: Thalamus and pain (Besson J-M, Guilbaud G, Peschanski M, eds), pp 21-34. New York: Elsevier.

Molander C, Xu Q, Grant G (1984) The cytoarchitectonic organization of the spinal cord in the rat. I. The lower thoracic and lumbosacral cord. J Comp Neurol 230:133-141.

Montaron MF, Deniau JM, Menetrey A, Glowinski J, Thierry AM (1996) Prefrontal cortex inputs of the nucleus accumbens-nigrothalamic circuit. Neuroscience 71:371-382.

Morgan MJ, Franklin KB (1991) Dopamine receptor subtypes and formalin test analgesia. Pharmacol Biochem Behav 40:317-322.

Neafsey EJ, Bold EL, Haas G, Hurley-Gius KM, Quirk G, Sievert CF, Terreberry RR (1986) The organization of the rat motor cortex: a microstimulation mapping study. Brain Res 396:77-96.
Oades RD, Halliday GM (1987) Ventral tegmental (A10) system: neurobiology. 1. Anatomy and connectivity. Brain Res 434:117-165.

Paalzow GH (1992) L-dopa induces opposing effects on pain in intact rats: (-)-sulpiride, SCH 23390 or alpha-methyl-DL-p-tyrosine methylester hydrochloride reveals profound hyperalgesia in large antinociceptive doses. J Pharmacol Exp Ther 263:470-479.

Pavlovic ZW, Bodnar RJ (1998) Opioid supraspinal analgesic synergy between the amygdala and periaqueductal gray in rats. Brain Res 779:158-169.

Paxinos G, Watson C (1986) The rat brain in stereotaxic coordinates. New York: Academic.

Reith ME, Li MY, Yan QS (1997) Extracellular dopamine, norepinephrine, and serotonin in the ventral tegmental area and nucleus accumbens of freely moving rats during intracerebral dialysis following systemic administration of cocaine and other uptake blockers. Psychopharmacology (Berl) 134:309-317.

Richfield EK, Young AB, Penney JB (1989) Comparative distributions of dopamine D-1 and D-2 receptors in the cerebral cortex of rats, cats, and monkeys. J Comp Neurol 286:409-426.

Rodgers RJ (1977) Elevation of aversive threshold in rats by intraamygdaloid injection of morphine sulphate. Pharmacol Biochem Behav 6:385-390.

Saadé NE, Atweh SF, Bahuth NB, Jabbur SJ (1997) Augmentation of nociceptive reflexes and chronic deafferentation pain by chemical lesions of either dopaminergic terminals or midbrain dopaminergic neurons. Brain Res 751:1-12.

Snow PJ, Lumb BM, Cervero F (1992) The representation of prolonged and intense, noxious somatic and visceral stimuli in the ventrolateral orbital cortex of the cat. Pain 48:89-99.

Suhara T, Nakayama K, Inoue O, Fukuda H, Shimizu M, Mori A, Tateno Y (1992) D1 dopamine receptor binding in mood disorders measured by positron emission tomography. Psychopharmacology 106:14-18.

Swanson LW (1992) Brain maps: structure of the rat brain. New York: Elsevier.

Tanaka T, Yokoo H, Mizoguchi K, Yoshida M, Tsuda A, Tanaka M (1991) Noradrenaline release in the rat amygdala is increased by stress: studies with intracerebral microdialysis. Brain Res 544:174-176.

Tassin JP, Bockaert J, Blanc G, Stinus L, Thierry AM, Lavielle S, Premont J, Glowinski J (1978) Topographical distribution of dopaminergic innervation and dopaminergic receptors of the anterior cerebral cortex of the rat. Brain Res 154:241-251.

Thierry AM, Pirot S, Gioanni Y, Glowinski J (1998) Dopamine function in the prefrontal cortex. Adv Pharmacol 42:717-720.

Tricklebank MD, Hutson PH, Curzon G (1984) Involvement of dopamine in the antinociceptive response to footshock. Psychopharmacology 82:185-188.

Van Eden CG, Hoorneman EM, Buijs RM, Matthijssen MA, Geffard M, Uylings HB (1987) Immunocytochemical localization of dopamine in the prefrontal cortex of the rat at the light and electron microscopical level. Neuroscience 22:849-862.

Watanabe M, Kodama T, Hikosaka K (1997) Increase of extracellular dopamine in primate prefrontal cortex during a working memory task. J Neurophysiol 78:2795-2798.

Yaksh TL, Yeung JC, Rudy TA (1976) Interaction of the medial thalamus and the periaqueductal gray in the modulation of the antinociceptive actions of morphine. In: Advances in pain research and therapy (Bonica JJ, Albe-Fessard D, eds), pp 621-628. New York: Raven.

Yaksh TL, Yeung JC, Rudy TA (1977) Medial thalamic lesions in the rat: effects on the nociceptive threshold and morphine antinociception. Neuropharmacology 16:107-114.

Yu LC, Han JS (1990) Habenula as a relay in the descending pathway from nucleus accumbens to periaqueductal grey subserving antinociception. Int J Neurosci 54:245-251.

Zito KA, Bechara A, Greenwood C, van der Kooy D (1988) The dopamine innervation of the visceral cortex mediates the aversive effects of opiates. Pharmacol Biochem Behav 30:693-699. 